\title{
From Editor-in-Chief
}

\section{New rule for manuscript revision}

Manuscript handling time (between arrival date of submitted manuscript and sending date of review result) of Anthropological Science is usually around two months. However, some authors are often slow in sending back their revised manuscripts after receiving review results. When handling editor requested considerable revision, it is understandable that revision takes some time. But if it takes too long, it implies that authors somehow lost their interest in their studies. Therefore, we decided to introduce new rule for manuscript revision, as follows.

Limit of Revising Period. If author is requested to revise submitted manuscript, revision must be sent to handling editor within one year after corresponding author received review result. When more than one year passed without return of revision, submitted manuscript is taken as retracted.

The above part was added to Instructions to Authors. I hope authors submitting to Anthropological Science will finish revision as soon as possible.

\section{WWW homepage of Anthropological Science}

Anthropological Science has its own WWW (World-Wide-Web) homepage, and its URL is:

$$
\text { http://spinner.lab.nig.ac.jp/AS/AS.html }
$$

This homepage includes list of editors, list of editorial board, instructions to authors, contents of all issues of Anthropological Science starting from vol. 101, abstracts of all articles appeared in Anthropological Science (vol. 101 and later), Author index for each volume of Anthropological Science (vol. 101 and later), full texts of book reviews appeared in Anthropological Science (vol. 106 and later). The homepage also contains A brief history of Anthropological Science, list of staff members of Anthropological Society of Nippon, and links to related WWW sites. I hope you visit our Journal homepage frequently.

\section{WWW homepage of forthcoming annual meeting at Hachioji in November}

As announced in last issue of Anthropological Science (vol. 106, No. 4), next annual meeting of Anthropological Society of Nippon will be held at Tokyo Metropolitan University Campus at Hachioji, Tokyo, from November 5 (Friday) to November 7 (Sunday). Professor Ohtsuki Fumio of Tokyo Metropolitan University is chairperson of its organizing committee. WWW homepage of this meeting will be open soon, and its URL is: http://www.sci.metro-u.ac.jp/jinrui/ 